Article

\title{
Dynamic Mechanical Behavior of Hierarchical Resin Honeycomb by 3D Printing
}

\author{
Huan Hong *, Menglei Hu and Liansong Dai
}

State Key Laboratory of Explosion Science and Technology, Beijing Institute of Technology, Beijing 100081, China; hmlbit2017@163.com (M.H.); dailiansong@yahoo.com (L.D.)

* Correspondence: hongh1021@bit.edu.cn; Tel.: +86-010-68918740

\section{check for}

updates

Citation: Hong, H.; Hu, M.; Dai, L. Dynamic Mechanical Behavior of Hierarchical Resin Honeycomb by 3D Printing. Polymers 2021, 13, 19. https: //dx.doi.org/10.3390/polym13010019

Received: 30 November 2020 Accepted: 18 December 2020 Published: 23 December 2020

Publisher's Note: MDPI stays neutral with regard to jurisdictional claims in published maps and institutional affiliations.

Copyright: (c) 2020 by the authors. Licensee MDPI, Basel, Switzerland. This article is an open access article distributed under the terms and conditions of the Creative Commons Attribution (CC BY) license (https: / / creativecommons.org/ licenses/by/4.0/).

\begin{abstract}
In this paper, surface projection micron stereo-lithography technology (P $\mu \mathrm{SL})$ by $3 \mathrm{D}$ printing was used to prepare two resin honeycomb materials with different levels, and the mechanical behavior of these materials was studied. The quasi-static compression experiment and the dynamic compression experiment were carried out on the samples using the in situ micro-compression testing machine and the Split Hopkinson bar (SHPB) experimental equipment. The stress-strain curves of these materials at different strain rates were obtained, and the energy absorption characteristic of materials with two different levels were analyzed. This article reveals that the collapse strength and energy absorption properties of the materials are related to the hierarchical level of honeycomb. Multi-level hierarchical honeycomb (MHH) has higher collapse strength and better energy absorption properties than single-level hierarchical honeycomb $(\mathrm{SHH})$. It turned out that increasing the hierarchical level of honeycomb could improve the mechanical properties of the materials. In the future development of products, the mechanical properties of hierarchical material by 3D printing can be further optimized through changing the level of the fractal structure.
\end{abstract}

Keywords: hierarchical honeycomb; 3D printing; collapse strength; energy absorption

\section{Introduction}

Lightweight and low-density cellular structures are widely used in automobile manufacturing, aerospace and other economic and defense fields. As typical low-density, lightweight cellular structures, honeycombs have excellent mechanical properties and good energy absorption properties [1-3]. The cell section of honeycomb materials is usually hexagonal, but it is also triangular, rectangular, or rhombic. The same as foam materials, the mechanical properties of honeycomb materials directly depend on the shape, size, and topology of the cells [4-6]. For example, the connection factor of the edge and the surface, the number of adjacent holes, etc., will change with the change from one structure to another and affect the mechanical behavior of the material in an important way. Especially under the impact load, the high frequency component of the load will control the dynamic response of the structure, and the influence of the spatial topology of the cell on the evolution of the local dynamic stress of the material becomes more and more significant. Therefore, in addition to the geometric parameters of the structure, how to establish the relationship between the topological parameters of the cell in the local space and the dynamic response of the material is also an important topic in the description of the mechanical characteristics of honeycomb materials.

Currently, many scholars studied the mechanical properties of honeycomb under different topologies using experimental and numerical simulation methods [7-10]. Hohe et al. [5,6] studied the elastic response of hexagonal, triangular, and quadrilateral honeycomb structures. Zhen et al. [11] numerically studied the dynamic mechanical properties of irregular random honeycomb structures under in-plane impact. Yamashita [12] analyzed the impact behavior of different cell honeycomb specifications with numerical and experimental methods. Zinno et al. [13] analyzed the multi-scale approach for the design of composite sandwich 
structures for train application. Wu and Jiang [14] studied the experimental results of six honeycomb structures under quasi-static load and axial load. Reza et al. [15] studied the in-plane compression mechanical properties of hexagonal honeycomb based on additive manufacturing technology by comparing experimental and calculated results. Different cell configurations [16-21] have been developed and explored over the years. To determine the relationship between compressive strength and cell size, some studies [22-25] found that changing some cellular size parameters could increase the compressive strength of the structure, thereby improving the mechanical properties of the honeycomb structures. Anna et al. [26] studied the energy absorption of honeycomb with regular cellular structures by 3D printing through static and dynamic loading. Many studies have shown that the mechanical and energy absorption properties of honeycomb largely rely on its cellular configuration and base material's properties. At present, based on the printing of existing material models and the construction of composite materials, 3D printing has seen some new applications. Kozior et al. [27] studied to improve the mechanical stability of an electrospinning nanofiber mat, which was combined with 3D printing technology to prepare a mechanically stable filter with a nanofiber surface. This study showed that the nanofiber mat had a strong adhesion to 3D printed scaffolds from thermoplastic polyurethane (TPU). At the same time, the adhesion of three-dimensional printing on textile fabrics [28] described the improvement of textile/polymer adhesion based on experimental research on adhesion in 3D printed textile/polymer composites and theoretical research on adhesion inside the 3D printed part.

A large amount of research currently focused on the change of the geometric parameters of the cell structure, while relatively little research has been done on multi-level hierarchical honeycomb structure designed by biologically inspired principles [29], which has seriously hindered its application in aerospace, rail, and automobile industry. Recently, the rapid development of 3D printing technology has met the design requirements of complex three-dimensional spatial structures, and it has provided a more convenient way for the preparation of porous composite materials and the optimization of fine-macro cross-scale [30]. In this paper, multi-level hierarchical honeycombs and single-level hierarchical honeycombs were fabricated by additive manufacturing to research their impact on mechanical behavior. The impact yield strength and energy absorption properties of these materials were investigated.

\section{Experimental Process}

\subsection{In Situ Micro-Compression Experimental Process}

In this study, two different samples (single-level hierarchical honeycomb (SHH) with a size of $4 \mathrm{~mm} \times 2.6 \mathrm{~mm}$ and multi-level hierarchical honeycomb (MHH) with a size of $4 \mathrm{~mm} \times 6 \mathrm{~mm}$ ) were fabricated as shown in Figure 1a,b. The resin honeycombs were manufactured by surface projection micron stereo-lithography technology $(\mathrm{P} \mu \mathrm{SL})$ technology (BMF Inc., Shenzhen, China) that meets the stereo lithography apparatus (SLA) technical standards in ISO/ASTM 52921 and had density in the range of $0.347-0.372 \mathrm{~g} / \mathrm{cm}^{3}$ (the parameters of resin listed in Tables 1 and 2), meaning a half-cell diameter of $0.14 \mathrm{~mm}$ and resin honeycomb $0.07 \mathrm{~mm}$ thick (see Figure 2). In view of the millimeter size of the samples, the in situ micro-compression loading test was performed by a MICROTEST2000 system (GATAN Inc., Pleasanton, CA, USA) with SEM (Figure 3). The system comprised a replaceable load sensor, a sample heater, a clamping device, and a compression head, and it is an important platform to observe and analyze the micro-deformation morphology and fracture mechanism of materials. The honeycomb samples were clamped between two compression heads with a dimension vision of $1 \mathrm{~mm} \times 1 \mathrm{~mm}$, such that an aperture of $0.28 \mathrm{~mm}$ diameter [31] was exposed in the vision (Figures 8 and 9). We respectively observed the deformation of the honeycombs and the deformation of the apertures by axial compression and radial compression. Before testing, the upper compression head was given a fixed speed and the samples were fixed on the base. While observing the deformation of the samples by SEM, the information of the loading was recorded. 

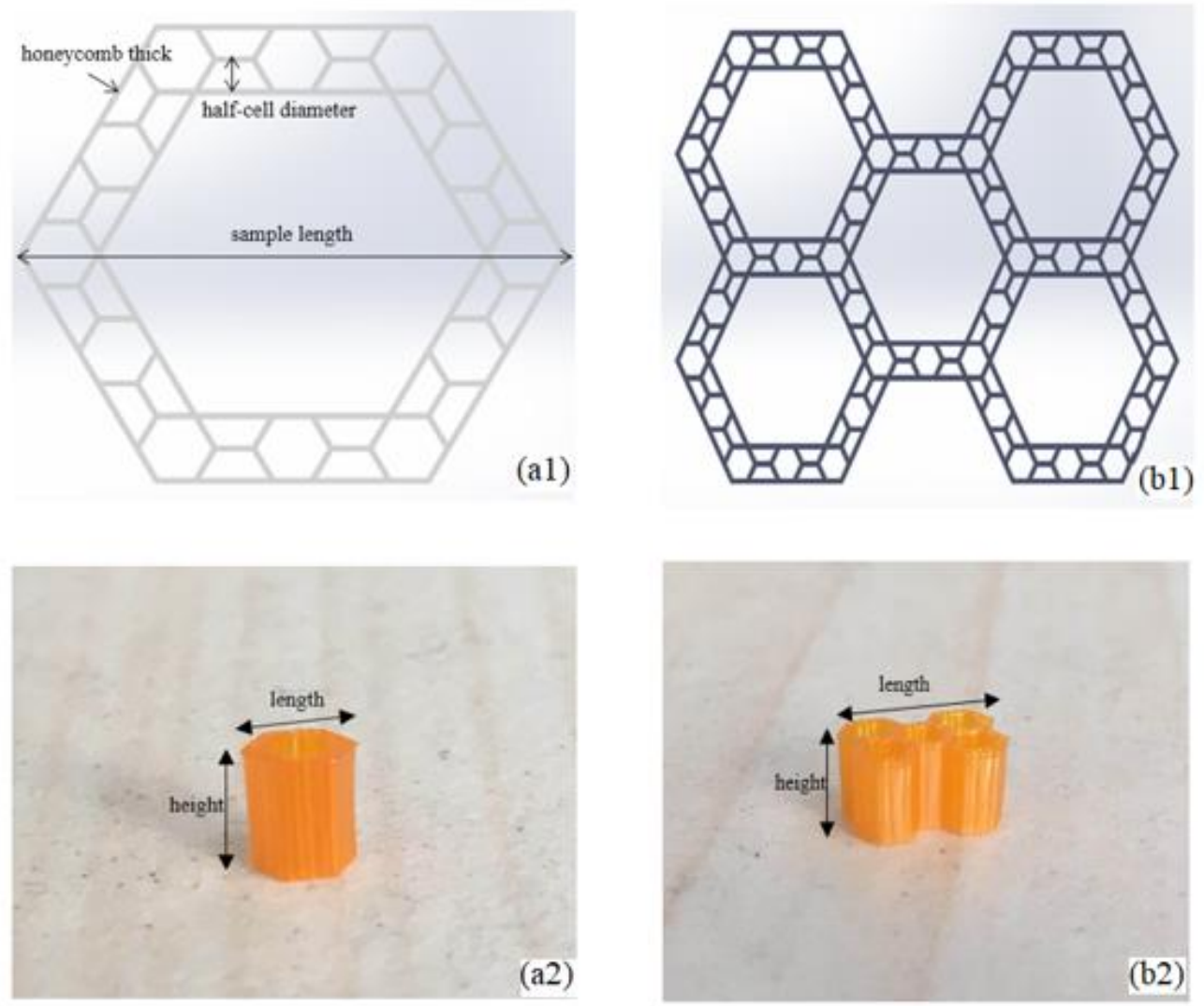

Figure 1. (a) Single-level hierarchical honeycomb (SHH), (b) multi-level hierarchical honeycomb (MHH).

Table 1. The parameters of resin material provided by manufacturers.

\begin{tabular}{cccccc}
\hline Resin Type & $\begin{array}{c}\text { Tensile } \\
\text { Strength } \\
\mathbf{( M P a )}\end{array}$ & $\begin{array}{c}\text { Impact } \\
\text { Strength } \\
\mathbf{( J / m )}\end{array}$ & $\begin{array}{c}\text { Elongation } \\
\text { at Break (\%) }\end{array}$ & Viscosity (CPs @ 25 $\left.{ }^{\circ} \mathbf{C}\right)$ & Hardness \\
\hline Tough & $50-60$ & $35-50$ & $8-12$ & $180-280$ & $\begin{array}{c}75-80 \\
(\text { ShoreD) }\end{array}$ \\
\hline
\end{tabular}

Table 2. The parameters of resin honeycombs.

\begin{tabular}{|c|c|c|c|c|c|c|}
\hline Material & $\begin{array}{c}\text { Sample } \\
\text { Length } \\
(\mathrm{mm})\end{array}$ & $\begin{array}{l}\text { Sample } \\
\text { Height } \\
(\mathrm{mm})\end{array}$ & $\begin{array}{l}\text { Honeycomb } \\
\text { Thick } \\
\text { (mm) }\end{array}$ & $\begin{array}{c}\text { Half-Cell } \\
\text { Diamete } \\
\text { r(mm) }\end{array}$ & $\begin{array}{c}\text { Sample } \\
\text { Weight (g) }\end{array}$ & $\begin{array}{r}\text { Relative } \\
\text { Density } \\
\left(\mathrm{g} / \mathrm{cm}^{3}\right)\end{array}$ \\
\hline $\mathrm{SHH}$ & 2.6 & 4 & 0.07 & 0.14 & 0.010 & 0.369 \\
\hline $\mathrm{MHH}$ & 6 & 4 & 0.07 & 0.14 & 0.049 & 0.347 \\
\hline
\end{tabular}

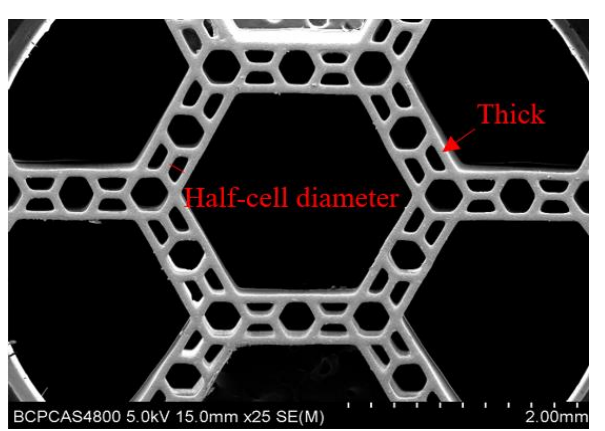

Figure 2. Multi-level honeycomb under SEM. 


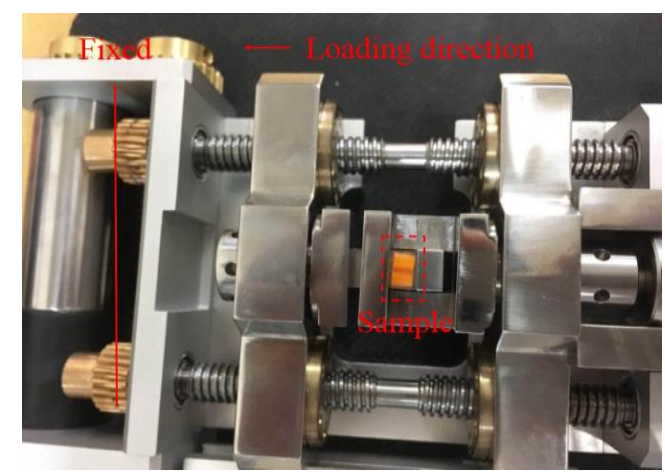

Figure 3. The in situ compression test equipment.

\subsection{Dynamic Experimental Process}

The Hopkinson pressure bar can realize loading experiments under a high strain rate $\left(10^{2}-10^{4} \mathrm{~s}^{-1}\right)$, and it is widely used by scholars engaged in dynamic mechanical research and related fields [32-34]. The core parts of the Hopkinson pressure bar device are two separate elastic waveguide bars (the incident and the transmitted bar). The sample is clamped between the two bars. The loading pulse is generated by the striker bar hitting the incident bar. The device is shown in Figure 4. An incident stress wave with a wavelength twice the length of the striker bar will be generated in the incident bar. When the incident stress wave reaches the sample, part of it is reflected back to the incident bar, and other part passes through the sample and reaches the transmitter bar. The transmitted stress wave is captured by the absorption bar and finally absorbed by the energy harvester. As shown in Figure 5, the signals of the incident wave, the reflected wave, and the transmitted wave have three amplitudes $\varepsilon_{I}, \varepsilon_{R}$, and $\varepsilon_{T}$, respectively. From these three signal values, we can deduce the stress-strain relationship of the sample [35].

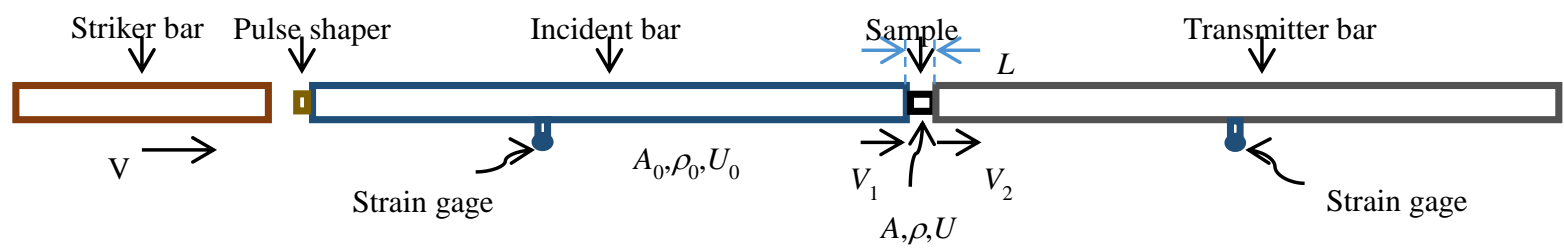

Figure 4. Schematic diagram of split Hopkinson pressure bar.
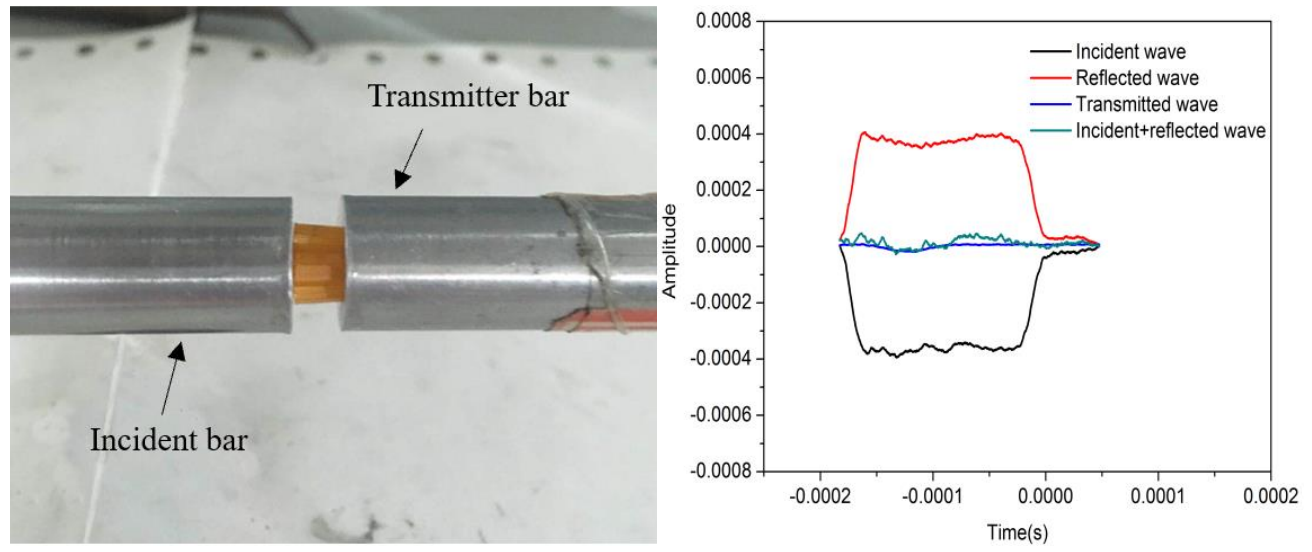

Figure 5. Experimental process and pulse signal by SHPB. 
According to the assumption of a one-dimensional stress wave in the bar, the stress $\sigma$, strain $\varepsilon$, and strain rate $\dot{\varepsilon}$ of the sample can be calculated by the following equations:

$$
\begin{gathered}
\sigma(t)=E_{0} \frac{A_{0}}{A} \varepsilon_{T}(t) \\
\varepsilon(t)=-\frac{2 C_{0}}{L} \varepsilon_{R} \\
\varepsilon(t)=-\frac{2 C_{0}}{L} \int_{0}^{t} \varepsilon_{R} d t
\end{gathered}
$$

Here, $E_{0}$ is the elastic modulus of the bar, $A_{0}$ is the cross-sectional area of the bar, $A$ is the cross-sectional area of the sample, $C_{0}$ is the elastic wave velocity of the bar, $L$ is the length of the sample, $\varepsilon_{T}(t)$ is the transmission strain, and $\varepsilon_{R}$ is the reflected strain.

In this paper, a $14 \mathrm{~mm}$ aluminum SHPB loading system was used to carry out an impact test, and the dynamic compression performance of the hierarchical material prepared by $3 \mathrm{D}$ printing in the strain rate range of $500-1500 \mathrm{~s}^{-1}$ was studied. In these experiments, the diameter of the striker bar and all the bars were $14 \mathrm{~mm}$, the length of the striker bar was $400 \mathrm{~mm}$, and the length of the incident bar and transmitted bar were both $2000 \mathrm{~mm}$. A set of strain gauges was attached between the incident bar and the transmitted bar, and each group has two strain gauges placed on the opposite surface of the bar to account for the transverse inertia effect of the stress wave. Taking into account the low impedance characteristics of the hierarchical materials and the attenuation effect of the bar on the stress wave, a semiconductor strain gauge was used on the transmitted bar, and a resistance strain gauge was attached to the incident bar. Each set of strain gauges was connected to a dynamic strain gauge to process and amplify the signal. Then, the incident pulse, reflected pulse, and transmitted pulse were collected by an oscilloscope.

\section{Results and Discussions}

The honeycomb samples were loading at low speed (MHH with the speed of 0.24 and $0.18 \mathrm{~mm} / \mathrm{min}$ (the corresponding strain rate is $10^{-3} \mathrm{~s}^{-1}$ ) respectively in axial and radial compression loading, $\mathrm{SHH}$ with the speed of 0.24 and $0.3 \mathrm{~mm} / \mathrm{min}$ (the corresponding strain rate is $10^{-3} \mathrm{~s}^{-1}$ ) respectively in axial and radial loading). The sample was clamped between two rigid indenters (see Figure 3). When loading, the right indenter moves to the left to compress the test piece, while the left indenter remains stationary. Before loading, we applied petroleum jelly to the surface of the left and right indenters to reduce the friction between the test piece and the indenter interface. All samples were loaded to compactness, the corresponding loading force and displacement could be obtained from the force at the right indenter and the displacement sensor, and the nominal stress-strain curve of the material could be obtained by calculation. For each group of working conditions, the test results with better repeatability were taken as the final test results.

Figures 6 and 7 show nominal stress-strain curves in quasi-static loading by an in situ micro-compression experiment. As it can be seen, very good reproducibility between curves was achieved. The stress-strain curves of the two levels of hierarchical materials show the same pattern in the same loading direction, and they can be divided into three stages: initial linear elastic section, stress plateau section, and stress compaction section. In the initial elastic region, the cell walls of the hierarchical materials enter the elastic deformation stage, and the stress-strain of the material shows a linear relationship; as the loading progresses, the cell wall begins to yield and gradually collapses, and the stress enters the platform section; finally, when all the cell walls are compacted, the stress curve rises rapidly during the compaction section. It is worth noting that there will be a sharp drop when the stress reaches the first peak, which is due to the internal cell wall of the material beginning to fail and fracture and collapse. When the remaining intact cell wall structure begins to load, the stress will rise again into the platform section. Different from the axially compressed long and smooth platform section, the stress platform section of the SHH material exhibits obvious oscillations, mainly due to the poor toughness of the base 
honeycomb material. The curve that appears in the elastic stage of individual materials is not smooth, and the difference is mainly related to the micro-defects of $3 \mathrm{D}$ printing materials.
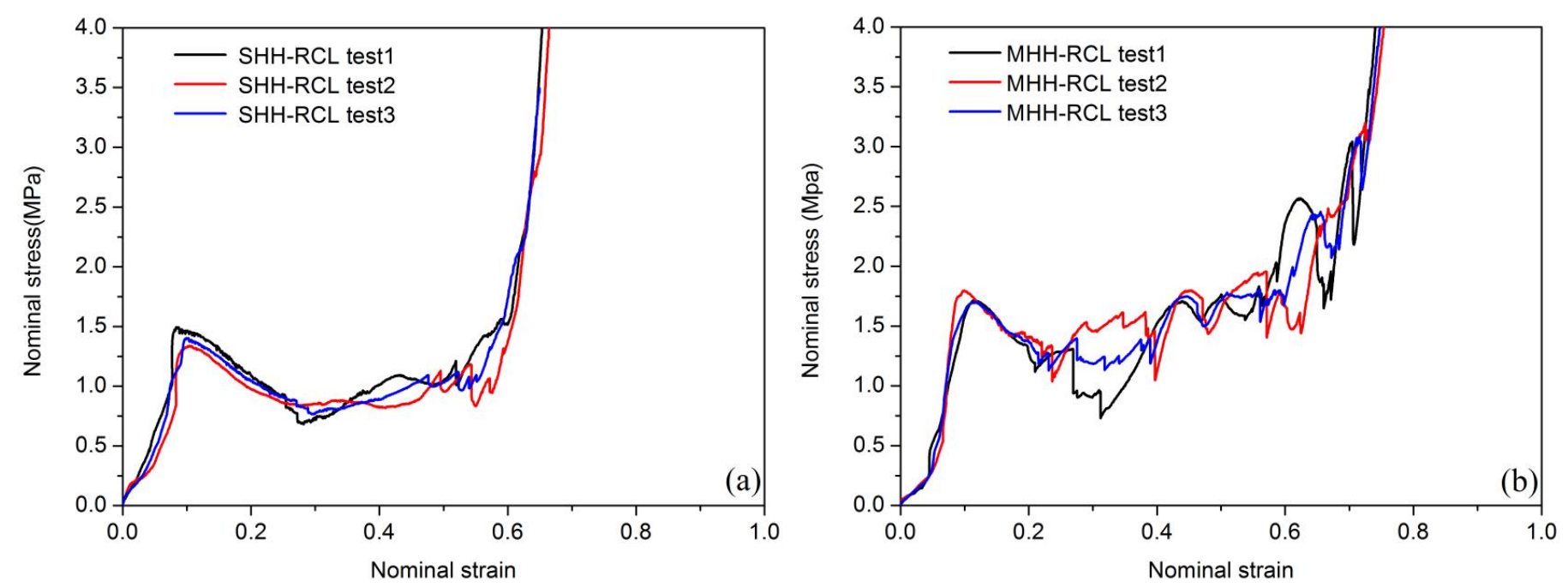

Figure 6. Nominal stress-strain curve of radial compression loading (RCL): (a) SHH-RCL test, (b) MHH-RCL test.
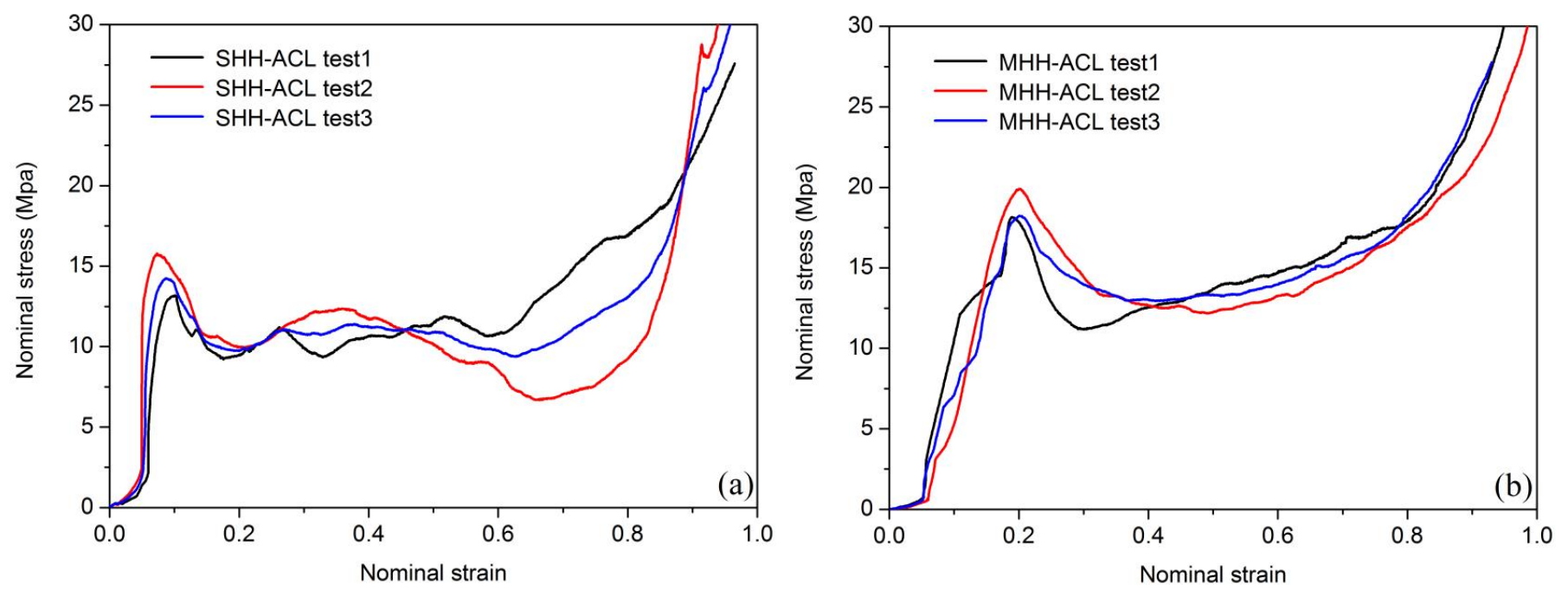

Figure 7. Nominal stress-strain curve of axial compression loading: (ACL) (a) SHH-ACL test, (b) MHH-ACL test.

The stress-strain curves of two honeycombs radial compressions are described in Figure 6. As shown in Figure 6a, stress rises slowly with the increase of strain. After the stress reaches the peak value of $1.49 \mathrm{MPa}$, the curve shows a stable plateau stage. A similar situation also occurs in Figure 6b. As shown in Figure 6b, the stress-strain curve peak value reached $1.75 \mathrm{MPa}$, which is significantly higher than that in Figure 6a. This shows that the radial compression loading peak value of $\mathrm{MHH}$ is $17.4 \%$ higher than $\mathrm{SHH}$. For axial compression loading, the peaks of the curves of the two honeycombs are higher than those of the radial compression loading, which can be seen in Figure 7a,b. As shown in Figure $7 \mathrm{a}$, the peaks of curves reached $15.79 \mathrm{MPa}$, and in Figure $7 \mathrm{~b}$, the peaks of curves reached $20.03 \mathrm{MPa}$. The axial compression loading peak value of $\mathrm{MHH}$ is $21.2 \%$ higher than $\mathrm{SHH}$. The results show that the compressive capacity of $\mathrm{MHH}$ is better than $\mathrm{SHH}$. Compared with the research results of $\mathrm{Xu}$ et al. [36], it is found that the quasi-static collapse strength of the hierarchical honeycomb structure is significantly higher than that of the ordinary honeycomb. 
In order to visually observe the compression deformation process of the multi-level honeycomb, we selected the deformation process perpendicular to the displacement direction of the vision. Figures 8 and 9 show the SHH material overall deformation process and $\mathrm{MHH}$ material local hinge deformation process, respectively. As shown in Figure 8, the first that started was the distortion of SHH external hinge. As the compression increased further, the honeycomb holes of the external hinge were twisted into clusters. When the crushing was over, the honeycomb holes on the upper and lower contacting with surfaces of the indenter would be distorted. As shown in Figure 9, the honeycomb hinge parallel to the surface of the indenter does not undergo significant deformation. Conversely, the angled internal hinges of honeycomb on both sides appear to be deformed as the crushing progresses and finally twisted into clusters.
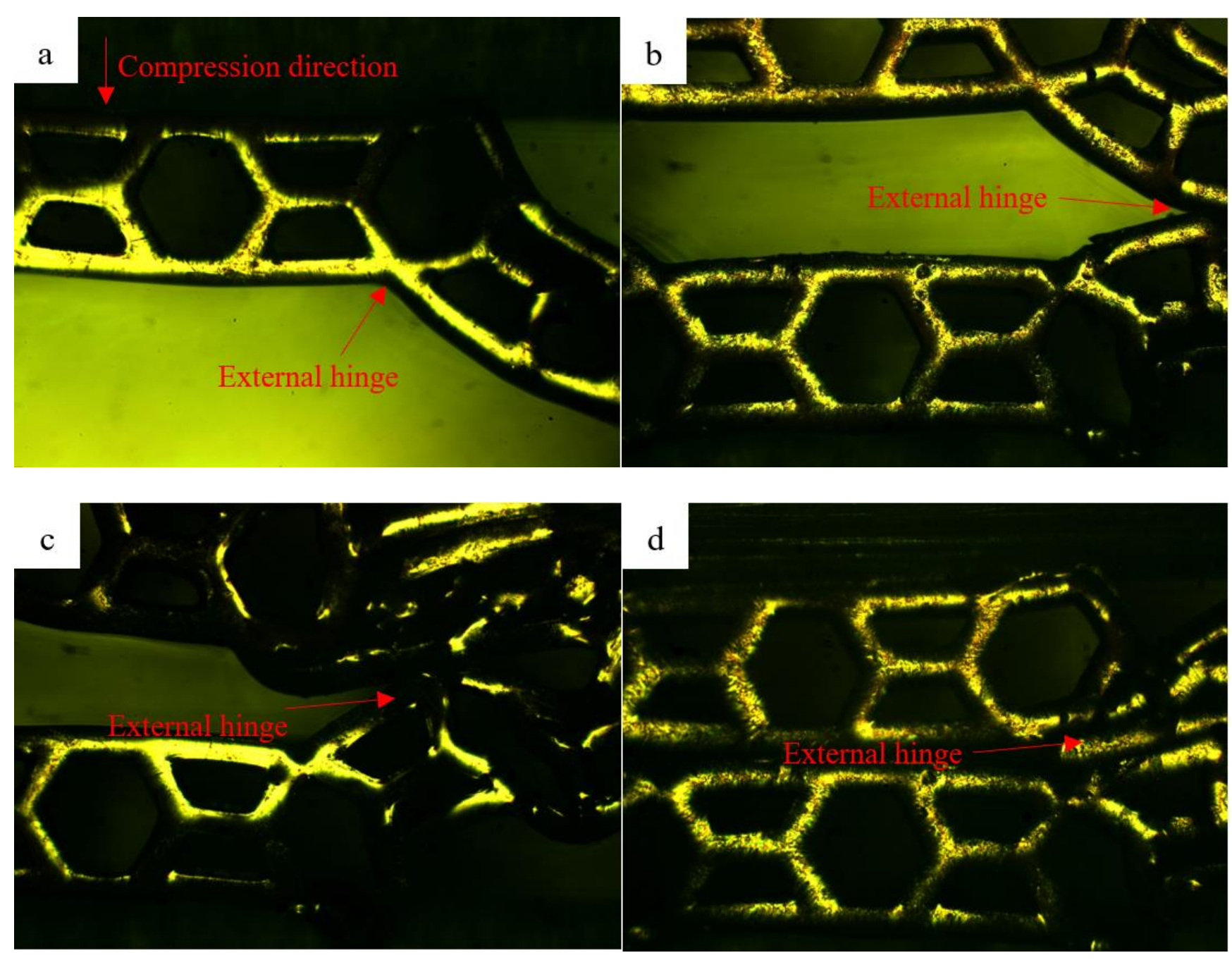

Figure 8. SHH material overall deformation process. (a) $\varepsilon=0.12,(\mathbf{b}) \varepsilon=0.29$, (c) $\varepsilon=0.38$, (d) $\varepsilon=0.56$.

Comparing the compression process in two directions, the load-carrying capacity and compression resistance exhibited by the axial compression process are better than the radial compression process. Therefore, in the future development of products, we should focus on the study of axial compression capability. Comparing the collapse strength of the two compression modes, it is not difficult to see that the collapse strength of the MHH material is obviously higher than that of the $\mathrm{SHH}$ material. Therefore, the mechanical properties of the $\mathrm{MHH}$ material can be further optimized by increasing the level of topological stages. 

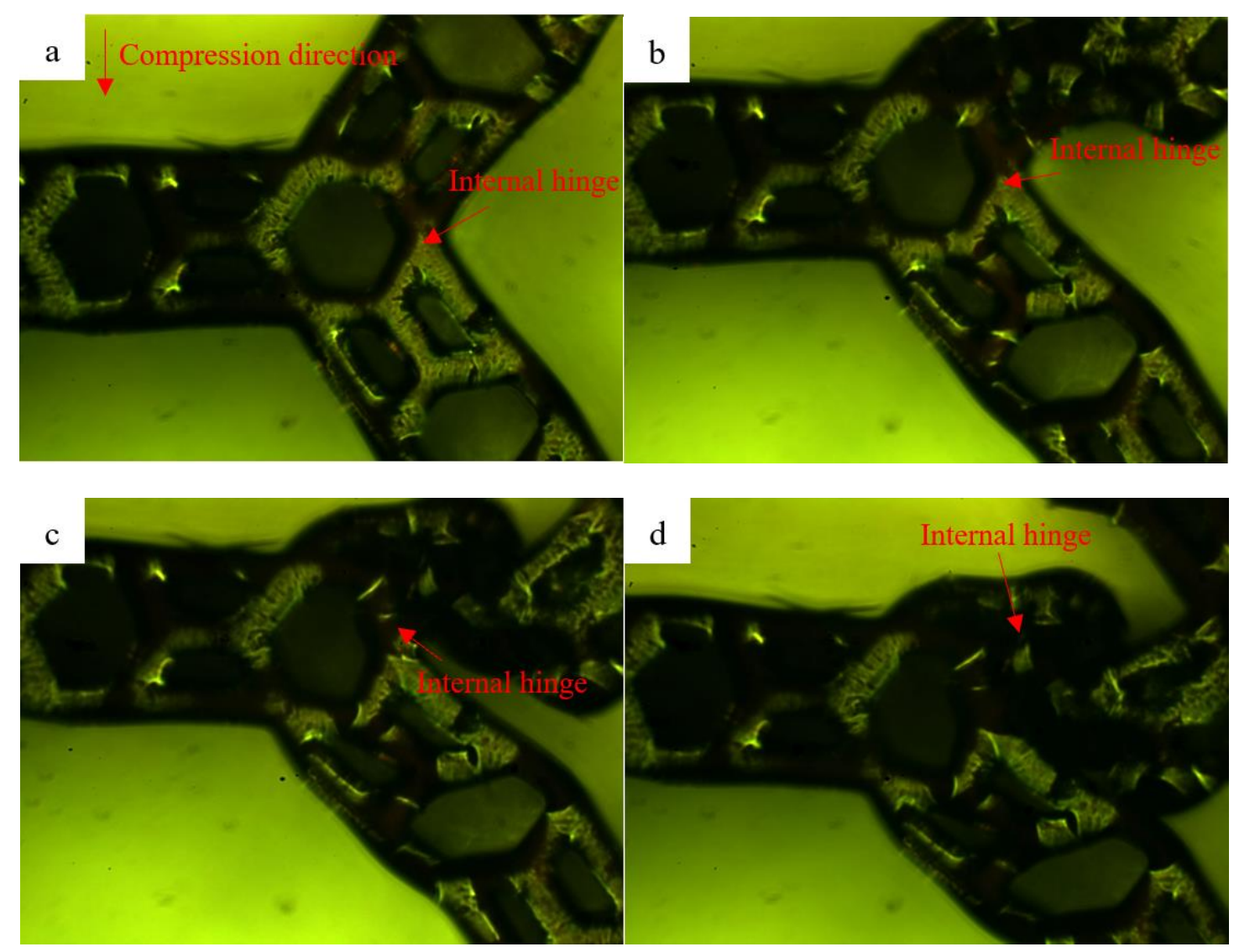

Figure 9. MHH material local hinge deformation process. (a) $\varepsilon=0.08,(\mathbf{b}) \varepsilon=0.23,(\mathbf{c})=0.36$, (d) $\varepsilon=0.52$.

In the SHPB impact test, the bullet speed range is $2-6 \mathrm{~m} / \mathrm{s}$, and the corresponding load strain rate range is $500-1500 \mathrm{~s}^{-1}$. Figure $10 \mathrm{a}, \mathrm{b}$ show the dynamic stress-strain curves of the two resin honeycomb materials with good repeatability under different strain rates. It can be seen from the figure that the dynamic stress-strain curve of the material is different from the quasi-static stress-strain curve. It has experienced an elastic stage before the stress reaches the initial peak, and then the stress begins to drop sharply due to the failure of the cell wall. All samples are compacted. Although the impact loading speed is low, due to the small size of the sample, the matrix resin material exhibits low toughness under dynamic loading, resulting that the dynamic stress-strain curve of the honeycomb specimens does not increase as the stress does under quasi-static loading. The platform stage is different from common metal porous materials. It can be seen from the figure that the two hierarchical materials of the unit cell size exhibit different strain rate sensitivity. Under the three strain rates studied, the stress-strain curve of the SHH material is basically similar, while the MHH material shows a certain strain rate sensitivity, and the collapse strength of the material increases at a high strain rate. Sahu [37] and Onck [38] pointed out that the larger the pore size of the foam material, the lower its strength. It can be seen from Figure 10 that although the MHH material has the same pore size as the SHH material, it has a lower relative density, and its collapse strength at different strain rates is higher than that of the SHH material. The above research shows that the reason for this difference may be related to the level number of honeycomb materials. The more levels honeycomb has, the higher the collapse strength. 

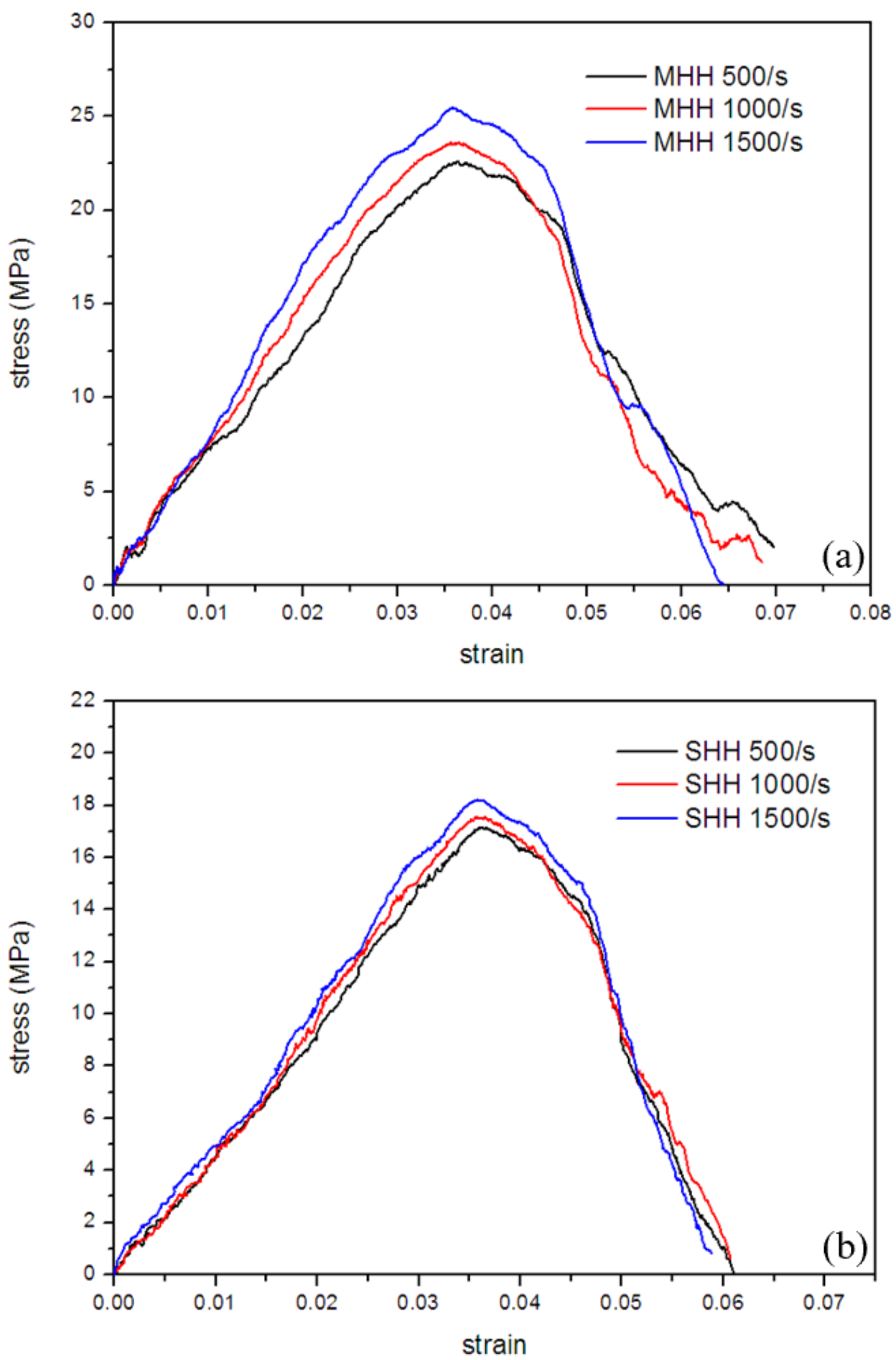

Figure 10. Dynamic stress-strain curve of resin hierarchical honeycomb materials: (a) MHH, (b) SHH.

In the past, many scholars discussed the strain rate sensitivity of porous structures. Zheng et al. [39] pointed out that due to the change of material deformation, the strength of porous medium under high-speed impact loading is higher than that under quasistatic loading. However, under low-speed impact loading conditions, the strengthening mechanism of material strength is still unclear. Figure 11 and Table 3 show the collapse strength of two hierarchical honeycomb materials with different levels under different strain rates. It can be seen that the two honeycomb samples exhibit different strain rate sensitivity. As shown in MHH materials, when the strain rate increases from $0.001 \mathrm{~s}^{-1}$ to $1000 \mathrm{~s}^{-1}$ and $1500 \mathrm{~s}^{-1}$, the collapse strength increases by $17.78 \%$ and $27.21 \%$, respectively. 
However, as shown in SHH materials, the strain rate strengthening effect is not obvious. The material collapse strength only increases by $16.53 \%$ when the strain rate increases from 0.001 to $1500 \mathrm{~s}^{-1}$.

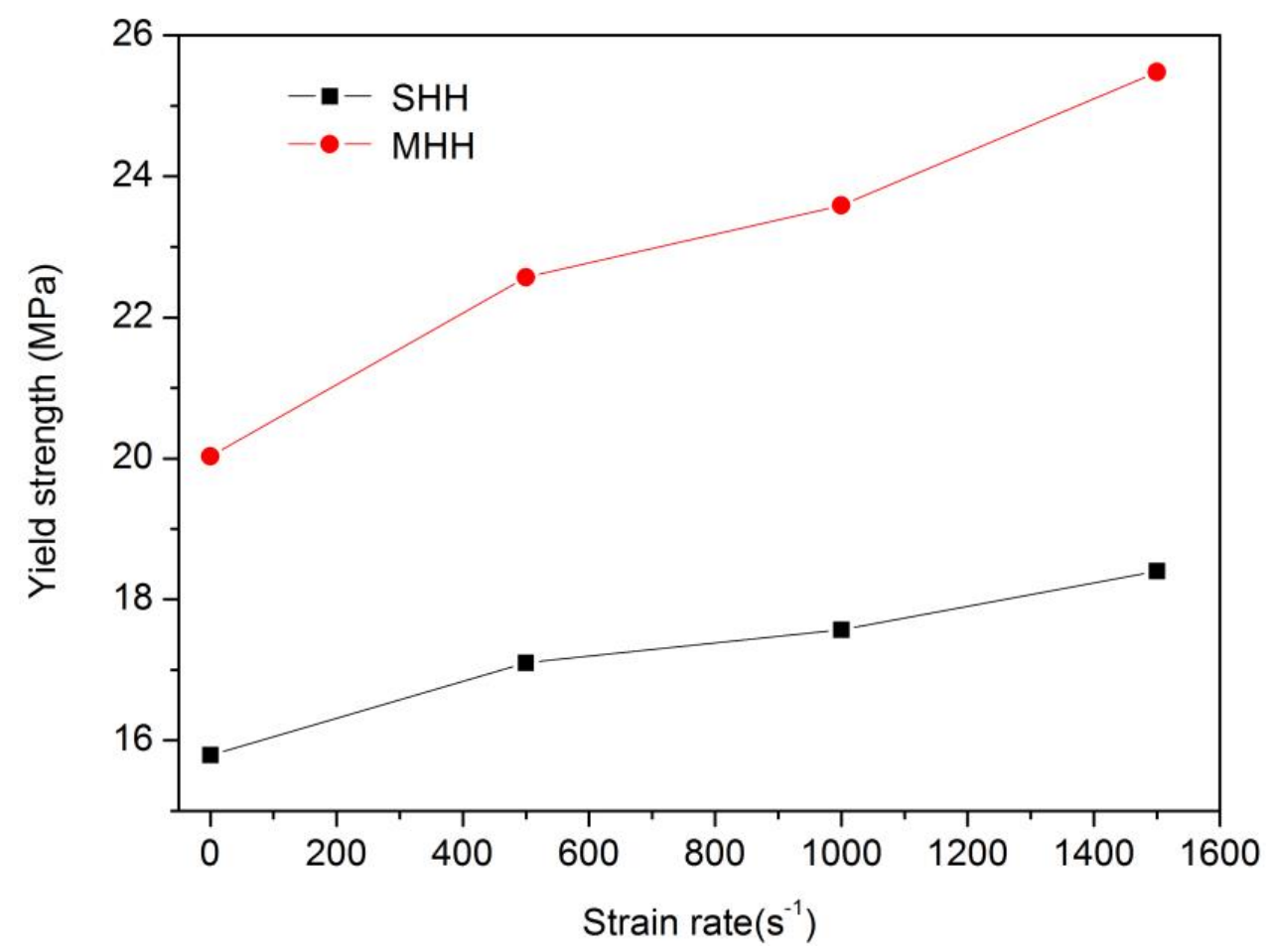

Figure 11. The yield strength of resin hierarchical honeycombs under different strain rates.

Table 3. The yield strength of resin honeycombs under different strain rates.

\begin{tabular}{ccc}
\hline Style of Honeycomb & Strain Rate/s $\mathbf{~}^{\mathbf{1}}$ & Yield Strength/MPa \\
\hline & 0.001 & 15.79 \\
$\mathrm{SHH}$ & 500 & 17.1 \\
& 1000 & 17.57 \\
& 1500 & 18.4 \\
$\mathrm{MHH}$ & 0.001 & 20.03 \\
& 500 & 22.57 \\
& 1000 & 23.59 \\
\hline
\end{tabular}

The different strain rate sensitivity of the two hierarchical honeycomb materials may be related to the difference in the micro-structure of the materials. Since the optimal preparation process parameters have not yet been determined, the quality of the single cell wall inside the honeycomb material is poor, and the cross-sectional dimension is not constant (see Figure 2). The micro-defects of the hole wall structure may reduce the strain rate strengthening effect of the material strength. Another reason that affects the strain rate sensitivity of materials may be related to the difference in the levels of honeycomb. The more levels the honeycomb has, the more obvious the strain rate strengthening effect. Due to the limited number of transverse unit cells of SHH material, the sample lacks transverse hinge constraints during impact loading, which aggravates the deformation and failure of the material, thereby reducing its strain rate sensitivity.

The honeycomb porous material is a typical buffering energy-absorbing protective material, so the energy absorption properties of resin hierarchical honeycomb materials under different strain rates are considered in this article. The work done by the external force is continuously folded through the honeycomb wall and converted into the shaping 
energy required for honeycomb deformation. The energy absorbed per unit volume of the honeycomb $(W)$ can be characterized by the area surrounded by the stress-strain curve, and the equation is as follows:

$$
W=\int_{0}^{\varepsilon_{p}} \sigma(\varepsilon) d \varepsilon
$$

Here, $\varepsilon_{p}$ is the strain of compressed before the densification phase, $\sigma$ is compressive stress, and $\varepsilon$ is compressive strain.

As an ideal energy absorbing structure, the ratio of the energy absorbed by the unit volume in the densification unit to the platform stress is an important parameter for describing the energy absorption characteristics. The expression equation for energy absorption efficiency $(\eta)$ is:

$$
\eta=\frac{\int_{0}^{\varepsilon_{p}} \sigma(\varepsilon) d \varepsilon}{\sigma_{\max } \cdot \varepsilon}
$$

Here, $\varepsilon_{p}$ is the strain of compressed before the densification phase, $\sigma_{\text {max }}$ is maximum stress on a given strain path, $\sigma$ is compressive stress, and $\varepsilon$ is compressive strain.

Figures 12 and 13 respectively show the energy absorption and energy absorption efficiency of resin honeycomb porous materials with different levels under quasi-static and dynamic loading. It can be seen from Figure 12a that under quasi-static loading, the energy absorption of the $\mathrm{MHH}$ material is slightly higher than that of the $\mathrm{SHH}$ material. However, it is worth noting that although the $\mathrm{MHH}$ material absorbs more energy, it cannot guarantee higher energy absorption efficiency. The main reason for this phenomenon is that the MHH material has higher stress and dense strain. It can be seen from Figure 13a that as the strain rate increases, the strain rate strengthening effect of the $\mathrm{MHH}$ material is more obvious, and the energy absorption of $\mathrm{MHH}$ is significantly higher than that of the $\mathrm{SHH}$ material. The comparison of energy absorption efficiency in Figure 13b shows that the energy absorption efficiency curve of resin honeycomb material is similar to that of foamed titanium [40], with obvious peaks, and the energy absorption efficiency of the material increases as the strain rate increases. Under dynamic loading, although the collapse strength of the material increases with the increasing of the strain rate, the low toughness of the material under dynamic loading causes the stress of the honeycomb material to decrease significantly after reaching the initial peak value, thereby reducing its energy absorption capacity. In short, whether it is quasi-static or dynamic loading, the energy absorption capacity of the MHH materials is significantly better.

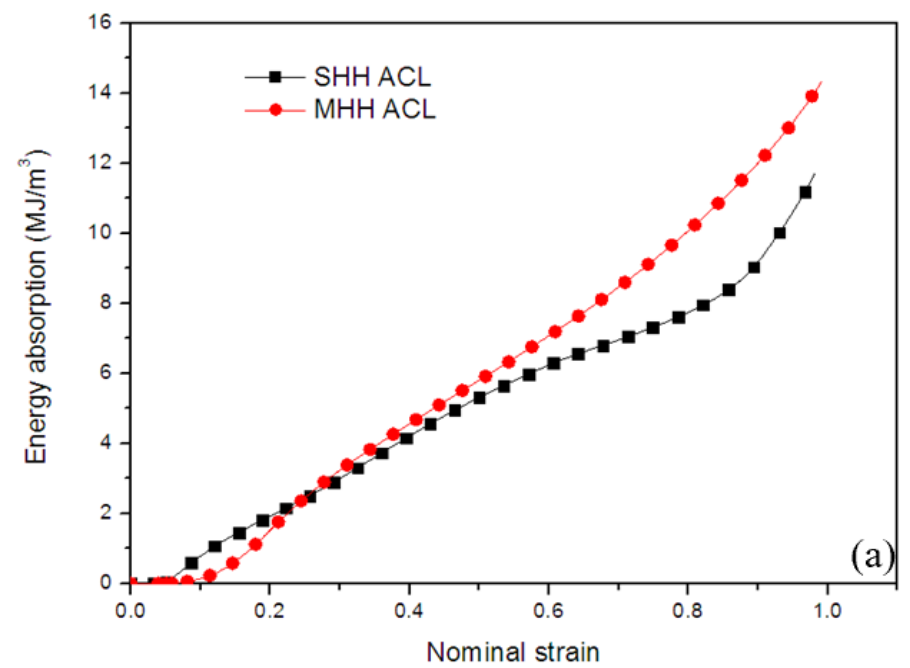

Figure 12. Cont. 


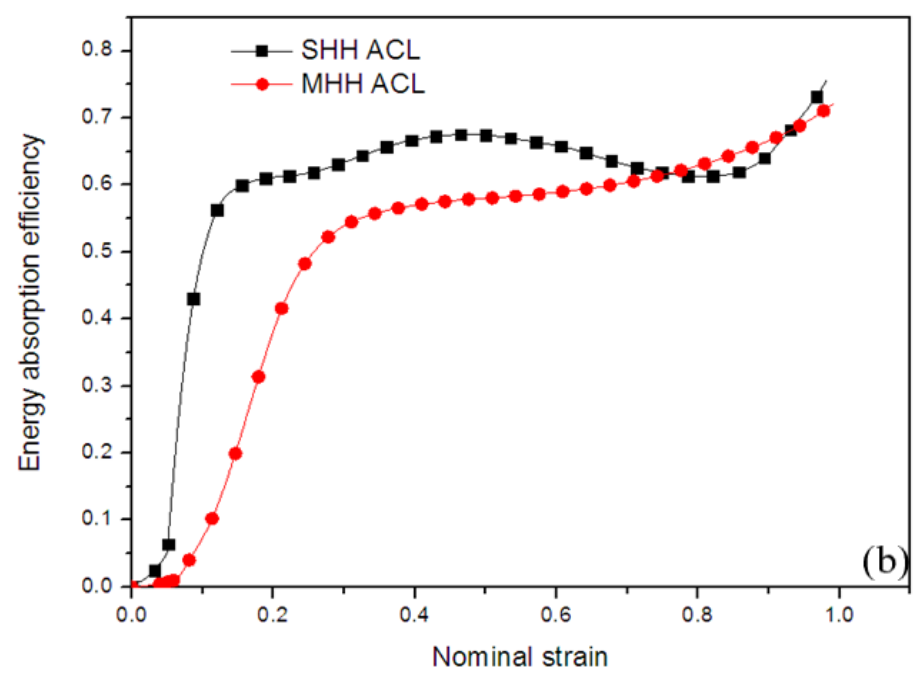

Figure 12. Energy absorption properties of resin honeycomb material under quasi-static loading: (a) Energy absorption, (b) Energy absorption efficiency.
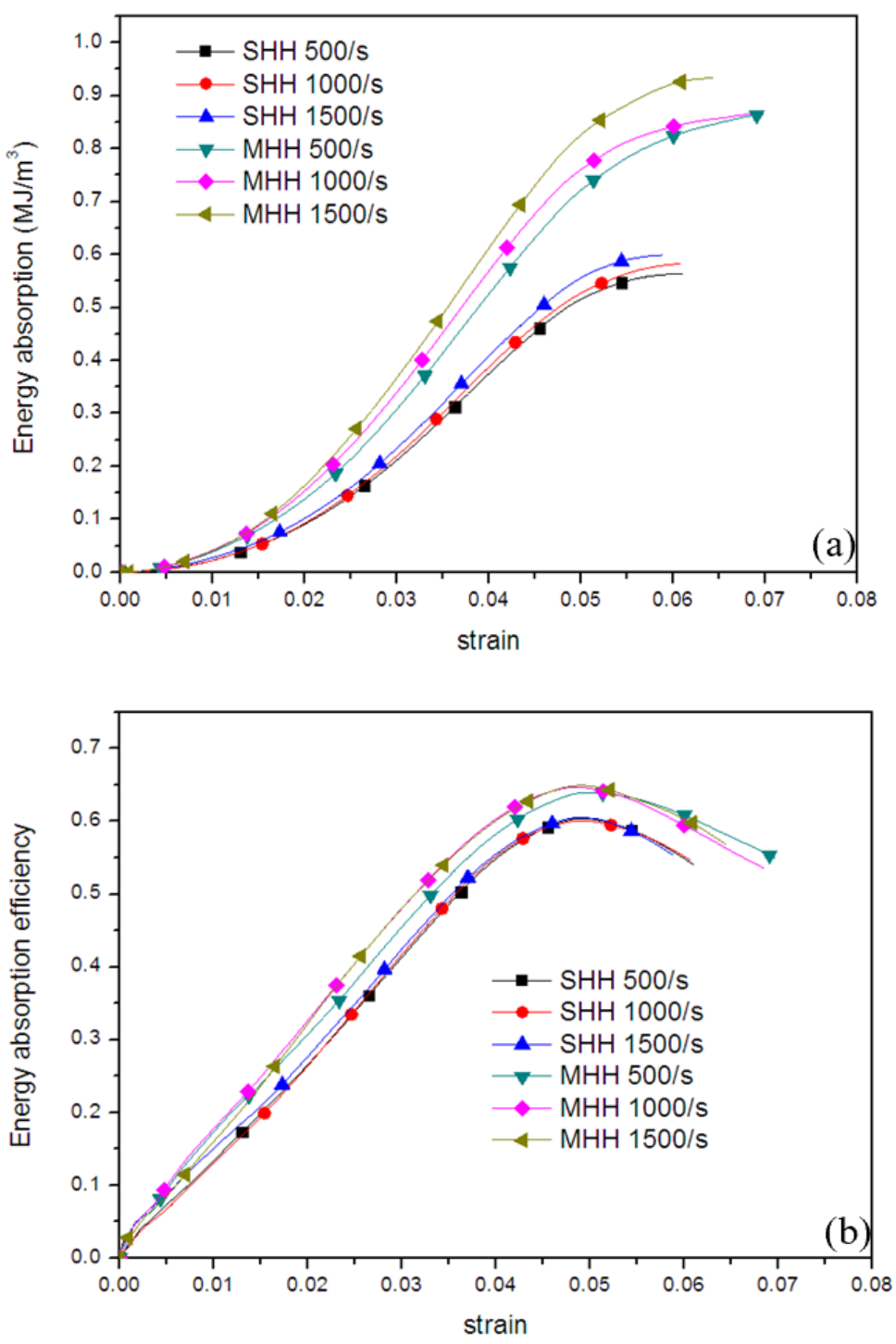

Figure 13. Energy absorption properties of resin honeycomb materials under dynamic loading of different strain rates: (a) Energy absorption, (b) Energy absorption efficiency. 


\section{Conclusions}

The paper presented the mechanical properties of hierarchical resin honeycombs. With the goal of light energy absorption of materials, the collapse strength and energy absorption efficiency of honeycombs with different levels under quasi-static and dynamic loading conditions are analyzed and compared. Based on the results obtained, the following can be stated:

(1) Under quasi-static loading, by comparing the experimental curves of the two compression directions, we find that the axial compression bearing capacity of the sample is higher than the radial compression. In future research, we should focus on the axial compression capability of honeycomb.

(2) Both under quasi-static and dynamic loading conditions, the collapse strength of the MHH materials is higher than that of the SHH materials. The mechanical properties of honeycomb materials can be improved by increasing the level of honeycomb cells. Under dynamic loading, the initial collapse strength of the honeycomb material shows a certain strain rate sensitivity, and the strain rate effect of the MHH material is more obvious. The two honeycomb materials with different levels show different strain rate sensitivity, which may be related to the difference of the material microstructure.

(3) As the strain rate increases, the energy absorption and energy absorption efficiency will also increase. In general, the MHH material has more energy absorption than the SHH material.

Author Contributions: H.H. designed the honeycomb structure, designed the in situ/dynamic tests and edited the documentation. M.H. helped complete the dynamic test and discussed the experimental data. L.D. made some suggestions on the experimental data and revised the manuscript. All authors have read and agreed to the published version of the manuscript.

Funding: This work is supported by the National Nature Science Foundation of China (11902037); the Opening Project of State Key Laboratory of Traction Power (TPL1701) and the Project of State Key Laboratory of Explosion Science and Technology (YBKT18-07).

Acknowledgments: Additionally, the authors would like to express gratitude to BMF Material Technology Inc. for help with the preparation of the honeycomb materials and Beijing University of Technology for help performing the in situ micro-compression tests.

Conflicts of Interest: The authors declare no conflict of interest.

\section{References}

1. Zhao, M.; Fan, X.; Fang, Q.-Z.; Wang, T. Experimental investigation of the fatigue of closed-cell aluminum alloy foam. Mater. Lett. 2015, 160, 68-71. [CrossRef]

2. Wang, Z.; Tian, H.; Lu, Z.; Zhou, W. High-speed axial impact of aluminum honeycomb-Experiments and simulations. Compos. Part B Eng. 2014, 56,1-8. [CrossRef]

3. Yan, C.; Hao, L.; Hussein, A.; Young, P.; Raymont, D. Advanced lightweight 316L stainless steel cellular lattice structures fabricated via selective laser melting. Mater. Des. 2014, 55, 533-541. [CrossRef]

4. Gibson, L.J.; Ashby, M.F. Cellular Solids: Structure and Properties; Cambridge University Press: Cambridge, UK, 1997.

5. Hohe, J.; Becker, W. Effective elastic properties of triangular grid structures. Compos. Struct. 1999, 45, 131-145. [CrossRef]

6. Hohe, J.; Beschorner, C.; Becker, W. Effective elastic properties of hexagonal and quadrilateral grid structures. Compos. Struct. 1999, 46, 73-89. [CrossRef]

7. Xiaomin, Z.; Zhang, L.; Zhang, P. Equivalent constitutive equations of honeycomb material using micro-polar theory to model thermo-mechanical interaction. Compos. Part B Eng. 2012, 43, 3081-3087. [CrossRef]

8. Mahmoudabadi, M.Z.; Sadighi, M. A theoretical and experimental study on metal hexagonal honeycomb crushing under quasi-static and low velocity impact loading. Mater. Sci. Eng. A 2011, 528, 4958-4966. [CrossRef]

9. Roy, R.; Nguyen, K.H.; Park, Y.B. Testing and modeling of Nomex (TM) honeycomb sandwich Panels with bolt insert. Compos. Part B Eng. 2014, 56, 762-769. [CrossRef]

10. Hazizan, A.; Cantwell, W. The low velocity impact response of an aluminium honeycomb sandwich structure. Compos. Part B Eng. 2003, 34, 679-687. [CrossRef]

11. Zheng, Z.; Yu, J.; Li, J. Dynamic crushing of 2D cellular structures: A finite element study. Int. J. Impact Eng. 2005, 32, 650-664. [CrossRef] 
12. Yamashita, M.; Gotoh, M. Impact behavior of honeycomb structures with various cell specifications-Numerical simulation and experiment. Int. J. Impact Eng. 2005, 32, 618-630. [CrossRef]

13. Zinno, A.; Fusco, E.; Prota, A.; Manfredi, G. Multiscale approach for the design of composite sandwich structures for train application. Compos. Struct. 2010, 92, 2208-2219. [CrossRef]

14. Wu, E.; Jiang, W.-S. Axial crush of metallic honeycombs. Int. J. Impact Eng. 1997, 19, 439-456. [CrossRef]

15. Hedayati, R.; Sadighi, M.; Aghdam, M.; Zadpoor, A.A. Mechanical Properties of Additively Manufactured Thick Honeycombs. Materials 2016, 9, 613. [CrossRef] [PubMed]

16. Deqiang, S.; Weihong, Z. Mean in-plane plateau stresses of hexagonal honeycomb cores under impact loadings. Compos. Struct. 2009, 91, 168-185. [CrossRef]

17. Hu, L.; He, X.; Wu, G.; Yu, T. Dynamic crushing of the circular-celled honeycombs under out-of-plane impact. Int. J. Impact Eng. 2015, 75, 150-161. [CrossRef]

18. Liu, Y.; Zhang, X.-C. The influence of cell micro-topology on the in-plane dynamic crushing of honeycombs. Int. J. Impact Eng. 2009, 36, 98-109. [CrossRef]

19. Liang, S.; Chen, H. Investigation on the square cell honeycomb structures under axial loading. Compos. Struct. 2006, 72, 446-454. [CrossRef]

20. Liu, L.; Wang, H.; Guan, Z. Experimental and numerical study on the mechanical response of Nomex honeycomb core under transverse loading. Compos. Struct. 2015, 121, 304-314. [CrossRef]

21. Zhang, X.; Zhang, H. Theoretical and numerical investigation on the crush resistance of rhombic and kagome honeycombs. Compos. Struct. 2013, 96, 143-152. [CrossRef]

22. Zhang, X.; Zhang, H.; Wen, Z. Experimental and numerical studies on the crush resistance of aluminum honeycombs with various cell configurations. Int. J. Impact Eng. 2014, 66, 48-59. [CrossRef]

23. Xu, S.; Beynon, J.H.; Ruan, D.; Yu, T.X. Strength enhancement of aluminum honeycombs caused by entrapped air under dynamic out-of-plane compression. Int. J. Impact Eng. 2012, 47, 1-13. [CrossRef]

24. Hu, L.; You, F.; Yu, T. Effect of cell-wall angle on the in-plane crushing behaviour of hexagonal honeycombs. Mater. Des. 2013, 46, 511-523. [CrossRef]

25. Deqiang, S.; Zhang, W.; Yanbin, W. Mean out-of-plane dynamic plateau stresses of hexagonal honeycomb cores under impact loadings. Compos. Struct. 2010, 92, 2609-2621. [CrossRef]

26. Antolak-Dudka, A.; Płatek, P.; Durejko, T.; Baranowski, P.; Małachowski, J.; Sarzyński, M.; Czujko, T. Static and Dynamic Loading Behavior of Ti6A14V Honeycomb Structures Manufactured by Laser Engineered Net Shaping (LENSTM) Technology. Materials 2019, 12, 1225. [CrossRef]

27. Kozior, T.; Mamun, A.; Trabelsi, M.; Wortmann, M.; Sabantina, L.; Ehrmann, A. Electrospinning on 3D Printed Polymers for Mechanically Stabilized Filter Composites. Polymers 2019, 11, 2034. [CrossRef]

28. Kozior, T.; Blachowicz, T.; Ehrmann, A. Adhesion of three-dimensional printing on textile fabrics: Inspiration from and for other research areas. J. Eng. Fibers Fabr. 2020, 15, 1-6. [CrossRef]

29. Fratzl, P.; Weinkamer, R. Nature's hierarchical materials. Prog. Mater. Sci. 2007, 52, 1263-1334. [CrossRef]

30. Zhang, Y.; Lu, M.; Wang, C.H.; Sun, G.; Li, G. Out-of-plane crashworthiness of bio-inspired self-similar regular hierarchical honeycombs. Compos. Struct. 2016, 144, 1-13. [CrossRef]

31. Liang, X.; Luo, H.; Mu, Y.; Wu, L.; Lin, H. Experimental study on stress attenuation in aluminum foam core sandwich panels in high-velocity impact. Mater. Lett. 2017, 203, 100-102. [CrossRef]

32. Deshpande, V.S.; Fleck, N.A. High strain rate compressive behavior of aluminum alloy foams. Int. J. Impact Eng. 2000, 24, 277-298. [CrossRef]

33. Mukai, T.; Kanahashi, H.; Miyoshi, T.; Mabuchi, M.; Nieh, T.; Higashi, K. Experimental study of energy absorption in a close-celled aluminum foam under dynamic loading. Scr. Mater. 1999, 40, 921-927. [CrossRef]

34. Wang, P.; Xu, S.; Li, Z.; Yang, J.; Zhang, C.; Zheng, H.; Hu, S. Experimental investigation on the strain-rate effect and inertia effect of closed-cell aluminum foam subjected to dynamic loading. Mater. Sci. Eng. A 2015, 620, 253-261. [CrossRef]

35. Marc, A.M. Dynamic Behavior of Materials; University of California: San Diego, CA, USA, 1994.

36. Xu, M.; Xu, Z.; Zhang, Z.; Lei, H.; Bai, Y.; Fang, D. Mechanical properties and energy absorption capability of AuxHex structure under in-plane compression: Theoretical and experimental studies. Int. J. Mech. Sci. 2019, 159, 43-57. [CrossRef]

37. Sahu, S.; Goel, M.; Mondal, D.; Das, S. High temperature compressive deformation behavior of ZA27-SiC foam. Mater. Sci. Eng. A 2014, 607, 162-172. [CrossRef]

38. Onck, P.; Andrews, E.; Gibson, L. Size effects in ductile cellular solids. Part I: Modeling. Int. J. Mech. Sci. 2001, 43, 681-699. [CrossRef]

39. Zheng, Z.; Wang, C.; Yu, J.; Reid, S.R.; Harrigan, J.J. Dynamic stress-strain states for metal foams using a 3D cellular model. J. Mech. Phys. Solids 2014, 72, 93-114. [CrossRef]

40. Smorygo, O.; Marukovich, A.; Mikutski, V.; Gokhale, A.; Reddy, G.J.; Kumar, J.V. High-porosity titanium foams by powder coated space holder compaction method. Mater. Lett. 2012, 83, 17-19. [CrossRef] 